OPEN ACCESS

Edited by:

Ye Tian,

Nanjing University, China

Reviewed by:

Shih-Ting Wang,

Brookhaven National Laboratory

(DOE), United States

Wang Shuang

Changchun Institute of Applied

Chemistry (CAS), China

*Correspondence:

Zoltán Dudás

dudas.zoltan@energia.mta.hu

†These authors have contributed equally to this work

Specialty section

This article was submitted to

Nanoscience,

a section of the journal

Frontiers in Chemistry

Received: 19 March 2020

Accepted: 12 May 2020

Published: 30 June 2020

Citation:

Borcan F, Len A, Bordejevic DA

Dudás Z, Tomescu MC and Valeanu AN (2020) Obtaining and Characterization of a Polydisperse

System Used as a Transmembrane Carrier for Isosorbide Derivatives.

Front. Chem. 8:492.

doi: 10.3389/fchem.2020.00492

\section{Obtaining and Characterization of a Polydisperse System Used as a Transmembrane Carrier for Isosorbide Derivatives}

\author{
Florin Borcan ${ }^{1 \dagger}$, Adél Len ${ }^{2,3 \dagger}$, Diana A. Bordejevic ${ }^{4}$, Zoltán Dudás ${ }^{2,5 *}$, Mirela C. Tomescu ${ }^{4}$ \\ and Adina N. Valeanu ${ }^{6}$
}

${ }^{1}$ The 1st Department (Analytical Chemistry), Faculty of Pharmacy, "Victor Babes" University of Medicine and Pharmacy, Timisoara, Romania, ${ }^{2}$ Neutron Spectroscopy Department, Centre for Energy Research, Hungarian Academy of Sciences, Budapest, Hungary, ${ }^{3}$ Faculty of Engineering and Information Technology, University of Pécs, Pécs, Hungary, ${ }^{4}$ The 5 th Department (Internal Medicine I), Faculty of Medicine, "Victor Babes" University of Medicine and Pharmacy, Timisoara, Romania, ${ }^{5}$ "Coriolan Drăgulescu" Institute of Chemistry, Romanian Academy, Timisoara, Romania, ${ }^{6}$ The 2nd Department, Faculty of Dental Medicine, "Victor Babes" University of Medicine and Pharmacy, Timisoara, Romania

Due to their effect of vasodilatation, isosorbide nitrates represent one of the most important and most used solutions for angina pectoris. Unfortunately, these compounds have multiple dose-related adverse drug reactions such as headache, weakness, mild dizziness, and occasionally heart rate changes, nausea, vomiting, and sweating. The main aims of this research were to obtain and to evaluate new polyurethane (PU) structures that can be used as a proper transmembrane carrier with an improved release kinetic. Chitosan-based PU structures were obtained by a polyaddition process between hexamethylene diisocyanate and a mixture of chitosan, butanediol, and polyethylene glycol in the presence of caffeine as a synthesis catalyst. The obtained samples (with and without isosorbide nitrates) were characterized regarding the encapsulation and release rate (UV-Vis spectra), chemical composition (FTIR), thermal stability (thermal analysis), morphology changes (SEM and SANS), and in vivo irritation tests. These methods revealed no significant differences between the two sample structures. Multipopulational structures with sizes between 73 and $310 \mathrm{~nm}$, with an increased tendency to form clusters and a high resistance to heat (up to $280^{\circ} \mathrm{C}$ ), were obtained. This study presents an alternative administration of isosorbide derivatives based on a PU carrier with a high biocompatibility and a prolonged release.

Keywords: chitosan, drug delivery, polyurethane, skin irritation, microstructural characterization

\section{INTRODUCTION}

Nitrate medications (nitroglycerin, sodium nitroprusside, isosorbide derivatives, etc.) are pharmaceutical agents with vasodilator effect (Polakowska et al., 2016). Thus, medication with isosorbide nitrates as active compounds is often used to prevent angina attacks and in the prophylactic treatments of angina pectoris (Yao et al., 2015). They can be also used in combination 
with cardiotonic glycosides, diuretics, and ACE inhibitors as adjuvant treatment of congestive heart failure (Kocyigit et al., 2017). Isosorbide nitrates include isosorbide dinitrate (IS-DN), 2-mononitrate (IS-2-MN), and 5-mononitrate (IS-5-MN), the last two being active metabolites of IS-DN and they exert qualitatively similar effects. A comparative study on these compounds reveals that IS-2-MN induces a lower increase of cyclic guanosine monophosphate (cGMP) and less tolerance induction, and its vasodilator effect is probably due to other mechanisms than the stimulation of guanylate cyclase (Raddino et al., 2010). U. Thadani and T. Rodgers reported a series of problems due to the administration of isosorbide nitrates: $82 \%$ of patients accused headaches and $\sim 10 \%$ could not tolerate them due to dizziness and/or disabling headaches; severe hypotension cases accompanied by syncope were recorded; the combination of nitrates and phosphodiesterase- 5 inhibitors used together for the treatment of erectile dysfunction induces a major decrease of blood tension and might lead to death (Thadani and Rodgers, 2006).

The particles used as carriers of isosorbide derivatives have a very long history: Hirayama et al. (1988) described three decades ago the obtaining and the physicochemical properties of a carrier, based on heptakis(2,6-di-O-ethyl)beta-cyclodextrin whose dissolution and IS-DN release rates were significantly decreased after the complexation with the cyclodextrin. Microcapsules based on hydroxypropyl cellulose with three different particle populations were developed by Yang et al. (2006) in order to obtain an improved kinetic model. A possible synergistic effect of IS-5-MN liposomalization and addition of glycerol in a transdermal carrier was studied in vitro by Barichello et al. (2017); they have applied both liposomal and aqueous solution with and without glycerol and they have found that glycerol facilitates the skin permeation while the liposomalization process leads to the drug accumulation. Most recently, the research team of Steinbach et al. (2017) has developed microemulsions with ceramide nanoparticles containing isosorbide and they have assessed the retarder action ex vivo in a Franz diffusion cell. Their results proved that ceramide particles present a better penetration in the upper layers of the skin without any irritating effect.

The usual routes for drug administration (oral, inhalable, intramuscular/intravenous, topical, and rectal) are selected depending on the drug formula, its toxicity and metabolic pathway, and the part of the body that is treated (Turner et al., 2011). Unfortunately, these classical routes are not always effective to assure the optimal dose of every drug to its specific receptor; there are several important drugs (e.g., hormones) with dosage inside the body whose gradual release is often a problem. The development of drug delivery systems, based on recent nano-sciences developments and on improved knowledge about the body membranes, represents a revolutionary advantage for many medications. Nowadays, organic and inorganic carriers are synthesized to solve two main problems: to avoid the adverse events (the side effects) and to modify the physicochemical properties of drugs in order to improve their transmembrane transfer (Solano-Umana et al., 2015).
The advantage of a polydisperse system used as a drug carrier consists in the gaining of a balance between the endocytosis-dependent cellular uptake and the amount of the encapsulated therapeutic compound; different pathways such as clathrin-caveolin-independent, caveolin-dependent, and clathrin-mediated are specific to nanoparticles, while the particles over $100 \mathrm{~nm}$ use macro-pinocytosis and phagocytosis to transfer their load (Danaei et al., 2018). On the other hand, the degradation of particles and their release rate depend on the type of carrier, the loading capacity, and the length of polymer chains. A polydisperse system containing particles with different sizes behaves rather like a slow-release delivery system. The interest for the prolonged released formulations containing isosorbide nitrates started more than four decades ago; R. Bonn has obtained capsules with isosorbide mononitrate that ensures a long-lasting effect (Bonn, 1988). Another long-acting formulation based on a controlled membrane principle was developed after 10 years (Prakash and Markham, 1999) and a comprehensive review describing the need of a prolonged release for this class of drugs was published in the same year (Gunasekara and Noble, 1999).

Polyurethanes (PUs) appeared in the laboratory of Prof. Otto Bayer at IG. Farbenindustrie Leverkusen (Germany) almost one century ago (Gama et al., 2018). There are many types of PU-based materials that look and behave very differently from each other. The main areas of their application are as follows: buildings (thermal insulation, sandwich panels, rigid columns, and other elements of architectural design), refrigeration (thermal insulation of refrigerators and freezers), automotive industry (car dashboard and steering wheel, door panels), furniture (cabinets, elastic mattresses, and pillows), textiles (camping products, adhesives for footwear), etc. Early use of PU in medicine was reported by Boretos and Pierce; they observed its vascular acceptability in experimental heart-assist pump chambers and arterial cannulae (Hasirci and Aksoy, 2007). In the last four decades, the use of PU covers many other medical fields such as cardiovascular devices (catheters, vascular prostheses, pacemakers), reconstructive surgery materials (wound dressings, breast implants, maxillofacial prostheses), and obstetrics and gynecology (condoms, contraceptive sponges; Vermette and Griesser, 2001). Basu et al. (2016) present a series of drug carriers based on PUs: nanoparticle systems, stimulus-responsive systems, shape-memory systems, etc.

The development of a poly(tetramethylene glycol)/isosorbidebased PU elastomer has been reported by Kim et al. (2014). It was found that this highly elastic and biocompatible PU presents increased mechanical properties and it can be used for soft tissue augmentation and regeneration. A similar study describing a PU with self-healing properties (Kim et al., 2019) has revealed that the replacement of traditional chain extenders (such as 1,4-butanediol or 1,6-hexanediol) with isosorbide or isomannide leads to materials with improved mechanical properties. Our research team already synthesized PU nano- and micro-structures with low release rates used as transmembrane delivery systems for different natural extracts (Munteanu et al., 2017; Borcan et al., 2018a,b,c, 2019). The aim of this study was to obtain and to characterize a chitosan-based PU that 
can assure a constant release of isosorbide derivatives for a prolonged time.

\section{MATERIALS AND METHODS}

\section{Reagents}

Chitosan-based PU structures were obtained using the following reagents: hexamethylene diisocyanate (HDI), polyethylene glycol (PEG 200), and caffeine were obtained from Merck (Darmstadt, Germany); acetic acid 96\%, acetone, and $\mathrm{HCl}$ $1 \mathrm{~N}$ were obtained from Chimopar SA (Bucharest, Romania); 1,4-butanediol (BD) was purchased from Carl Roth $\mathrm{GmbH}$ (Karlsruhe, Germany); and chitosan was from Oxford Lab. Chem. (Vasai-Virar, Maharashtra, India). These reagents were of commercial reagent grade; they were kept under the conditions indicated by the manufacturer and they were used without further purifications.

Inorganic salts such as $\mathrm{NaCl}, \mathrm{KCl}, \mathrm{NaHCO}_{3}, \mathrm{Na}_{2} \mathrm{HPO}_{4}$, $\mathrm{K}_{2} \mathrm{HPO}_{4}, \mathrm{KH}_{2} \mathrm{PO}_{4}$, and $\mathrm{MgCl}_{2}$ were purchased from Chimopar SA (Bucharest, Romania), and they were used to prepare a simulated body fluid; they were of analytical grade and they were previously heated to remove the crystallization water.

\section{Synthesis of Chitosan-Based PU Structures}

The first step was the solubilization of chitosan: $100.0 \mathrm{mg}$ chitosan, $2.5 \mathrm{ml}$ acetic acid, and $5 \mathrm{ml} \mathrm{HCl}$ were added to $50 \mathrm{ml}$ of double deionized distilled water, and they were mixed on a Velp hot plate stirrer with $300 \mathrm{rpm}$, at $45^{\circ} \mathrm{C}$ for $10 \mathrm{~min}$. In the second step, the aqueous phase was prepared by using the entire previously obtained chitosan solution and $2.0 \mathrm{ml}$ of BD, $3.0 \mathrm{ml}$ of PEG 200, and $40.0 \mathrm{mg}$ of caffeine as catalyst of PU synthesis. This mixture was further sonicated with a powerful lab homogenizer (Hielscher UP200S) for another $15 \mathrm{~min}$, and after that, it was split into two different $100-\mathrm{ml}$ polymerization flasks in equal volumes. Ten milliliters of aqueous solution containing $3 \mathrm{mmol}$ IS-2-MN, $1 \mathrm{mmol}$ IS-5-MN, and $5 \mathrm{mmol}$ IS-DN was added in one of the flasks, and it was labeled as PU_1 (sample containing isosorbide nitrates), while the other flask was labeled PU_0 (reference sample, empty chitosan-based PU without nitrates).
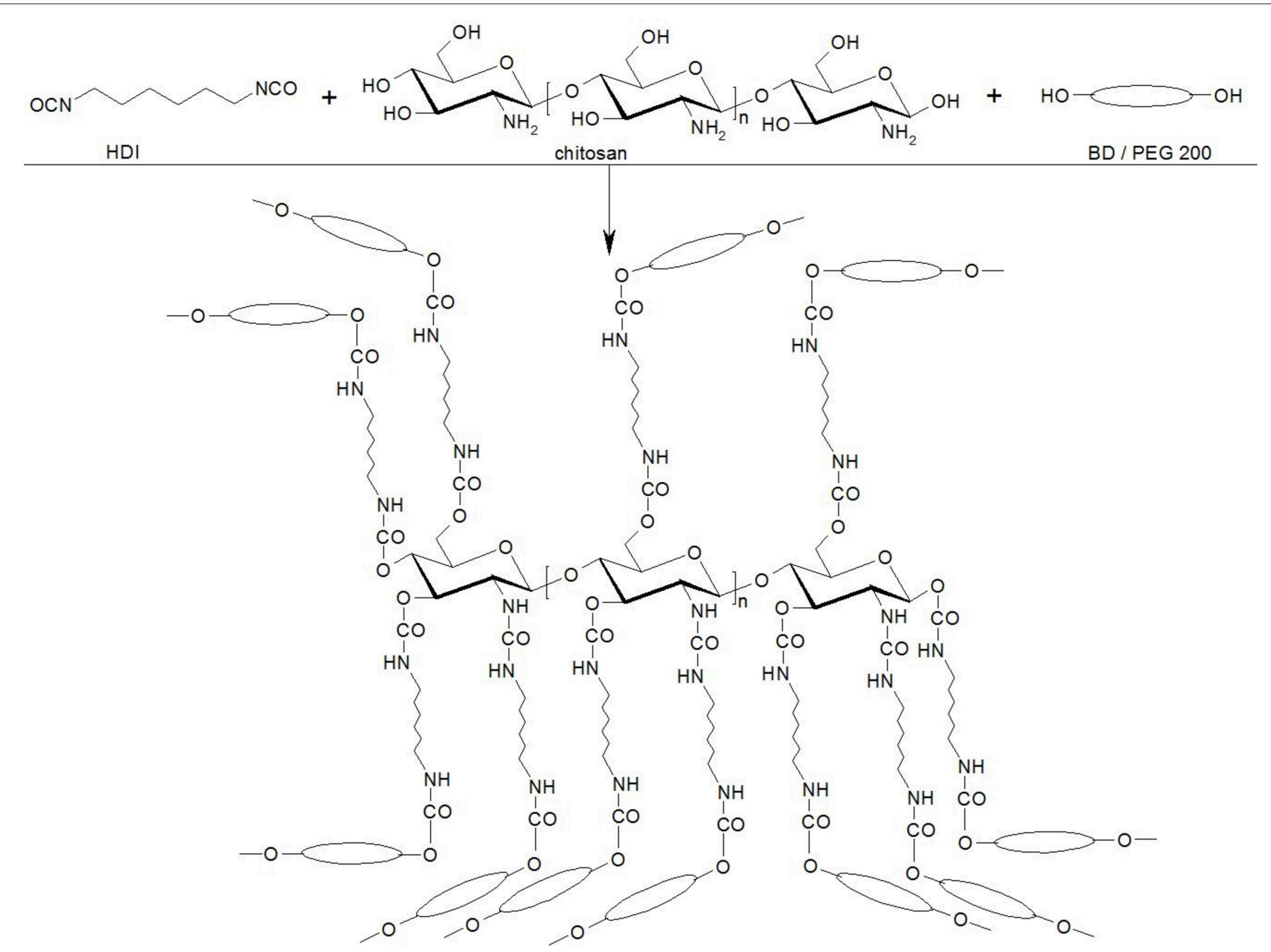

FIGURE 1 | The chemical reactions between the main raw materials. 
In the third step of the synthesis, the organic phase was prepared in a 100-ml Berzelius beaker: $14.0 \mathrm{ml}$ of HDI was dissolved in $50 \mathrm{ml}$ of acetone, and the mixture was homogenized for $10 \mathrm{~min}$ and was poured in the two polymerization flasks in equal volumes.

The content of these flasks was stirred with $300 \mathrm{rpm}$, at room temperature for $90 \mathrm{~min}$ in order to complete all chemical reactions of macromolecular chains.

In the last step, the synthesis products were washed three times with a mixture of acetone and water $(1: 1, \mathrm{v} / \mathrm{v})$ and they were slowly dried by being kept as thin layers at room temperature till no mass change was observed.

Figure 1 presents the starting chemical reactions that happen around the chitosan molecules and lead to a three-dimensional growth of chains.

\section{Drug Encapsulation Efficiency}

The percentage of drug that was successfully entrapped inside a carrier can be calculated by reporting the free/untrapped drug to the total amount of drug added (Bouchemal et al., 2004). Figure 2 presents the UV spectra of isosorbide nitrates and of PU structures obtained on a UVi Line 9,400 Spectrophotometer (SI Analytics, Germany). It can be observed that IS-DN has no maximum peak, while the two isosorbide mononitrate isomers' (IS-MN) spectra overlap perfectly. A calibration curve, describing the dependence between the absorbance at $220 \mathrm{~nm}$ and the concentration of IS-2-MN standard solutions, was drawn in accordance with Tsai et al. (1994).

\section{Drug Release Kinetics}

The cumulative percentage of isosorbide derivatives that were released at a specific moment was determined by maintaining the chitosan-based PU structures with derivatives (sample PU_1) in a degradation medium (a simulated body fluid, SBF according to T. Kokubo recipe; Quan et al., 2016) for 3 weeks; the procedure is described in detail in one of our previous papers (Borcan et al., 2018c).

A

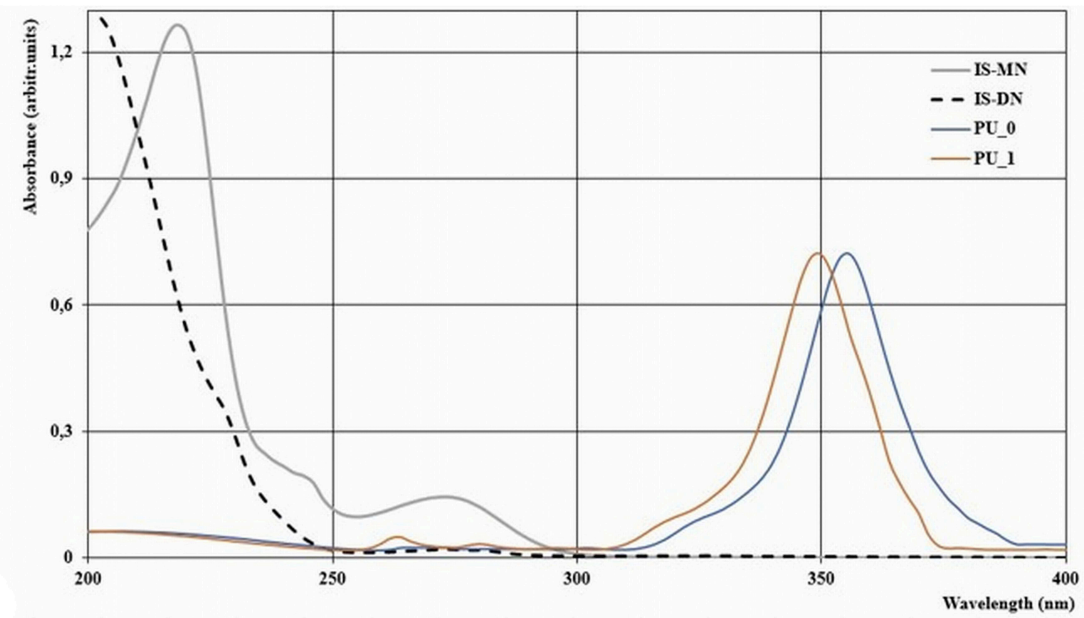

B

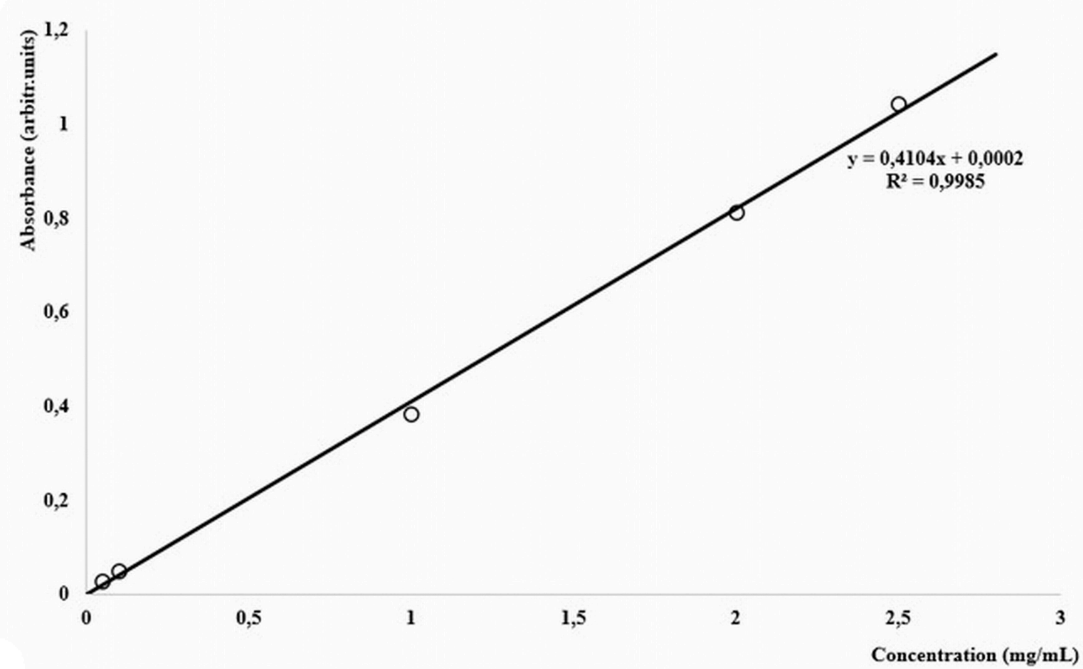

FIGURE 2 | (A) UV-Vis spectra of samples and (B) calibration curve of isosorbide mononitrate. 


\section{Thermal Analysis}

The resistance of samples to heating and the study of thermal degradation processes were done using a DSC1 (Mettler-Toledo, Switzerland); $4 \pm 0.3$-mg samples were placed in aluminum crucibles with pierced lids, and they were heated in an inert atmosphere between 30 and $300^{\circ} \mathrm{C}$ with $5^{\circ} \mathrm{C} / \mathrm{min}$.

\section{Zetasizer Measurements}

The size and the surface charge of the chitosan-based PU structures with and without isosorbide derivatives were assessed using a Cordouan Zetasizer (Cordouan Technol., France). The following input parameters of the size module were set: evaluation temperature $\left(25^{\circ} \mathrm{C}\right)$, time intervals $(12$ $\mu \mathrm{s})$, number of channels (225), laser power (80 $\pm 5 \%$ ), acquisition mode (statistical mode with noise limit; minimum 6 acquisitions/sample), and analysis mode (Cumulants). In the case of Zeta potential module, the parameters were quartz cuvette, temperature $\left(25^{\circ} \mathrm{C}\right)$, laser power $(75 \pm 5 \%)$, applied field (automatic), medium resolution, 3 measures/sequence, and Henry function (Smoluchowski).

\section{Scanning Electron Microscopy (SEM)}

The shape and surface morphology of the PU nano-/microparticles were determined from micrographs recorded with a TESCAN 3 VEGA scanning electron microscope secondary

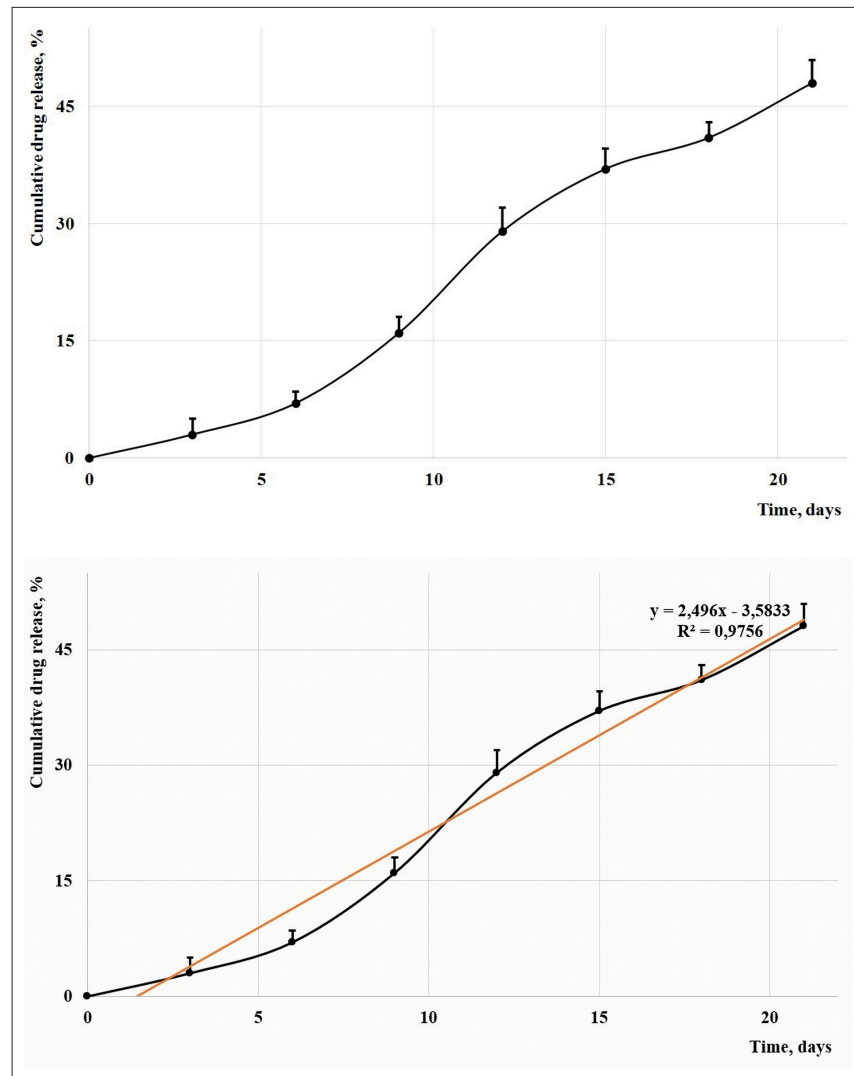

FIGURE 3 | The cumulative release of isosorbide derivatives. electron detector. The high-voltage value was set at $20 \mathrm{kV}$. The samples were tested in their natural form under vacuum.

\section{Fourier Transform Infrared Spectroscopy (FTIR)}

Differences on the chemical composition of the two samples' functional groups were analyzed by FTIR spectroscopy. Hereby, FTIR spectra were collected, using $\mathrm{KBr}$ pellets, through the use of a Cary 630 FTIR spectrophotometer (Agilent, USA), in the wavenumber ranging $400-4,000 \mathrm{~cm}^{-1}$.

\section{Small-Angle Neutron Scattering (SANS)}

SANS measurements were performed on the Yellow Submarine (YS) instrument at the Budapest Neutron Centre in Hungary. Neutrons with wavelengths of 4.2 and $10.2 \AA$ and sample-todetector distances of 1.15 and $5.25 \mathrm{~m}$ were chosen. This range of wave vectors corresponds to structural sizes ranging from 1 to $100 \mathrm{~nm}$. The samples were deposited in quartz cuvettes with $2-\mathrm{mm}$ thickness and they were placed for 30 to $60 \mathrm{~min}$ in an 8 -mm-diameter neutron beam.

\section{In vivo Evaluations}

Seven human volunteers ( 3 men and 4 women, between 25 and 37 years old) were used to evaluate the skin irritation caused by the products. The two synthesized samples (PU_0 and PU_1) and a mixture of isosorbide derivatives as reference were applied as solutions $(1: 20 \mathrm{w} / \mathrm{v})$ on three areas of the left anterior forearm every third day $(0.5 \mathrm{ml} /$ application $)$ and the determinations of the skin parameters were performed 25 min later on every treated area. The measurements were carried out with a MultiProbe Adapter from Courage\&Khazaka Electronics (Köln, Germany), equipped with a Tewameter ${ }^{\circledR}$ TM300 probe and a Mexameter ${ }^{\circledR}$ MX18 probe, by the same operator, at the same moment of the day for 15 days. The values are expressed as differences between after and before any application due to the differences in skin types of the analyzed volunteers.

\section{Statistics and Ethical Approval}

The statistical analyses were performed using IBM SPSS v.23; the results were expressed as mean \pm standard error. One-Way ANOVA and Bonferonni-Dunn tests were used to determine the statistical difference between experimental and blank values groups; ${ }^{* *}$ and $* * *$ indicate $p<0.01$ and $p<0.001$ on Figures 11, 12.

The research was done according to the principles of the Declaration of Helsinki. The authors declare that all procedures respect the specific regulations and standards: the study was first evaluated and approved by the Ethical Committee of "Victor Babes" University of Medicine and Pharmacy Timisoara, Romania. Every volunteer read and signed an informed consent and a signed informed consent for publication of the research results was also obtained.

\section{RESULTS}

Three-dimensional PU structures are often found among those materials that are preferably used in medical applications 
due to their easy and cheap production as well as to their unique combination of biocompatibility, sterilizability, durability, good mechanical properties, abrasion, and chemical resistance (Kikuchi et al., 2017).

\section{Drug Encapsulation Efficiency}

The difference between the most intense absorption positions of the empty PU structures $(360 \mathrm{~nm})$ and isosorbide mononitrates $(220 \mathrm{~nm})$ represents an important advantage in the evaluation of the concentration of the active substances in the studied solutions. Encapsulation efficiency equal to $72.3 \%$ was found by reporting the quantity of free mononitrates inside the washing mixture from the last synthesis step to the total amount of isosorbide mononitrates added to synthesis.

\section{Drug Release Kinetics}

Figure 3 presents the evolution of the cumulative percentage of isosorbide mononitrates that were released inside a simulated body fluid; 5 aliquots of each $0.4 \mathrm{ml}$ were replaced every third day with fresh medium, and their maximum absorption was found at $220 \mathrm{~nm}$; mean concentrations and standard deviation were used to explain the release profile.

\section{Thermal Analysis}

DSC curves (Figure 4) indicate a mild dehydration process during the samples' heating between 50 and $100^{\circ} \mathrm{C}$ (a large endothermic peak) and a good thermal stability up to $260-280^{\circ} \mathrm{C}$. No important difference was observed between the samples and no melting point of isosorbide derivatives was found, which indicates the absence of the isosorbide derivatives in their free form.

\section{Zetasizer Measurements}

Figures 5, 6 present the distribution of PU structure size. The complexity and multipopulation character of the samples are confirmed by their polydispersity index (PDI). Master curve, a very precious indicator for stable polydisperse samples, obtained using Pade-Laplace analysis, is defined by the averaged autocorrelation function over the whole run. PDI for sample PU_0 was found as 0.7 with five different structure populations between 73 and $408 \mathrm{~nm}$. Predominant populations were $112.2 \mathrm{~nm}$ (76.2\%) and $223.9 \mathrm{~nm}$ (18.6\%). PDI for sample PU_1 was found as 0.6 with four main populations between 104 and $310 \mathrm{~nm}$. Predominant populations were $123.1 \mathrm{~nm}(86.4 \%)$ and $309.1 \mathrm{~nm}$ (8.3\%). Zeta potential values determined as the mobility of structures in an electric field were $10.71 \mathrm{mV}$ (sample PU_0) and $9.55 \mathrm{mV}$ (sample PU_1), values that are specific to colloidal systems with a high tendency to form agglomerations of structures.

\section{Scanning Electron Microscopy (SEM)}

The aspect of samples studied by SEM at different magnifications $(220 \times, 500 \times, 1,000 \times$, and $1,500 \times)$ confirms the desired heterogeneity of chitosan-based PU structures (Figures 7, 8) without an explicit difference between the PU_0 and PU_1 samples.

\section{Fourier Transform Infrared Spectroscopy}

FTIR is one of the most important analysis methods in this domain. The diversity of PU functional groups justifies its use. PUs contain multiple urethane groups (-NH-CO-O-), but they are in balance with others: free hydroxyl $(-\mathrm{OH})$ and amine rests $\left(-\mathrm{NH}_{2},-\mathrm{NH}-\right)$ or functional groups specific

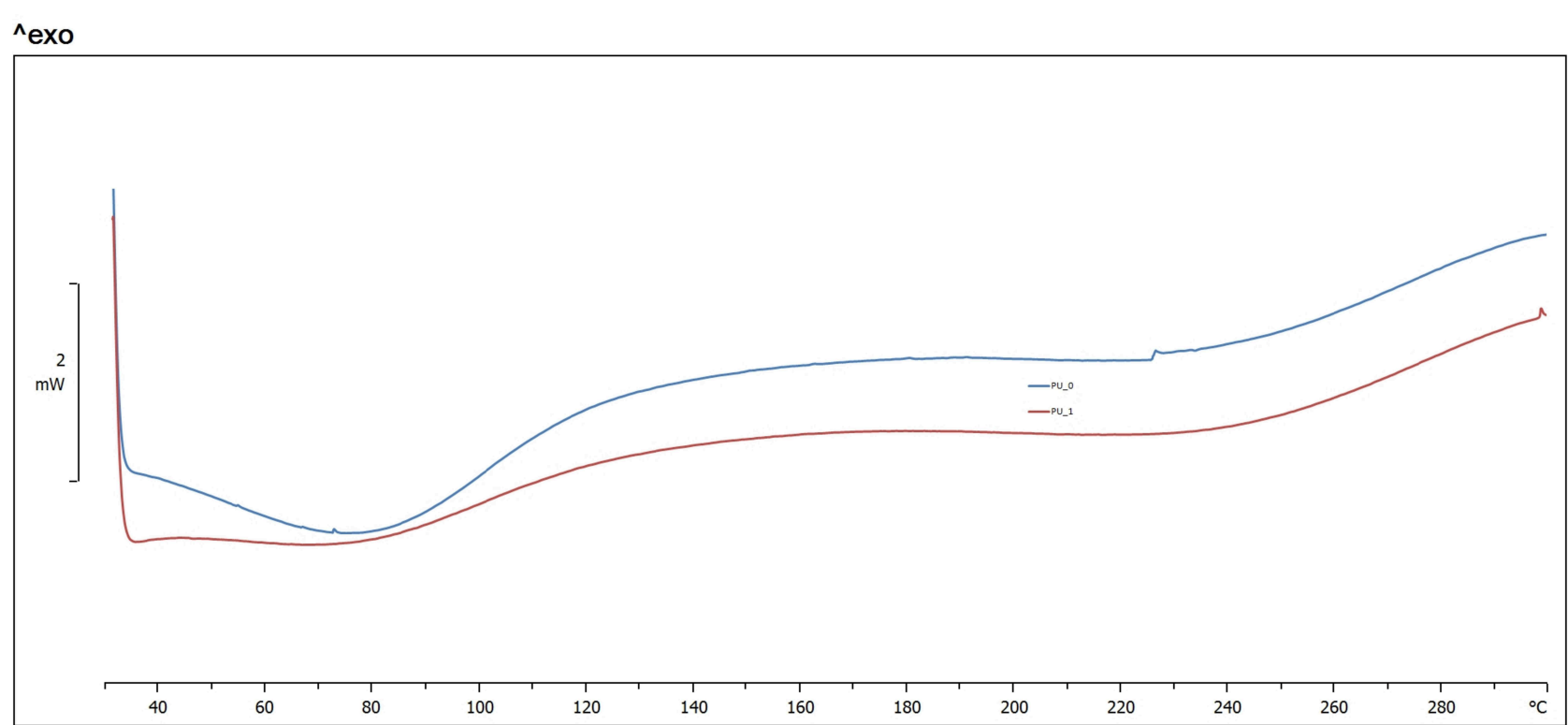

Lab: UMFT

FIGURE 4 | DSC thermograms of chitosan-based PU structures. 


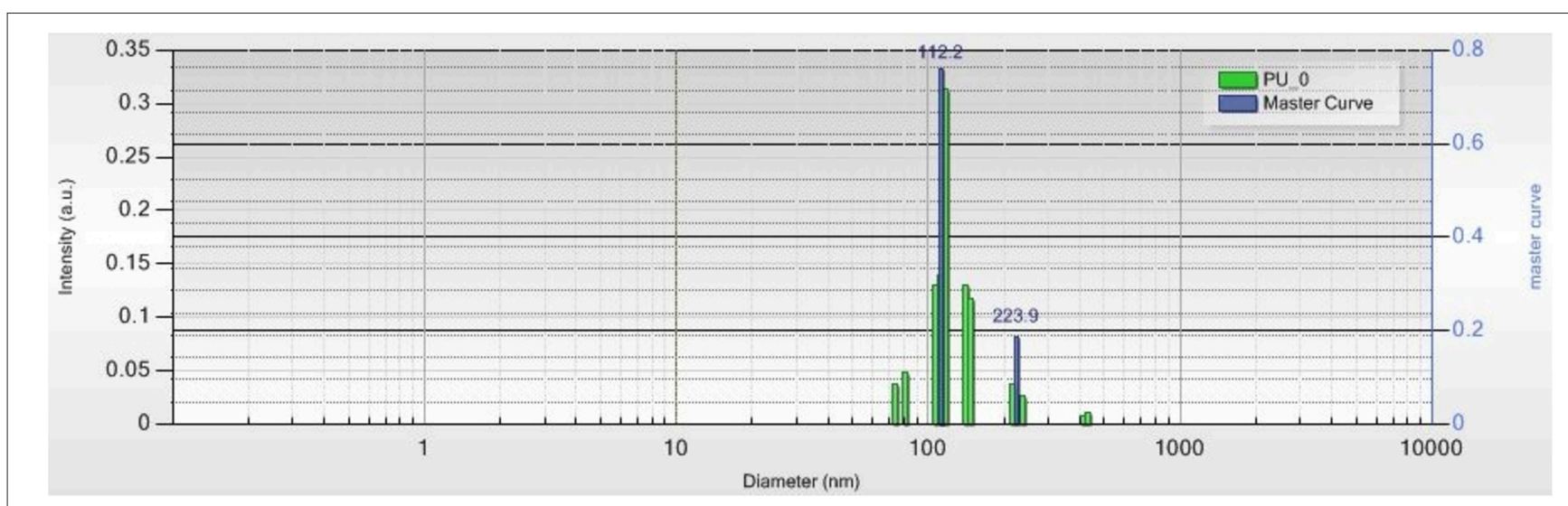

FIGURE 5 | The size distribution of structures from sample PU_0.

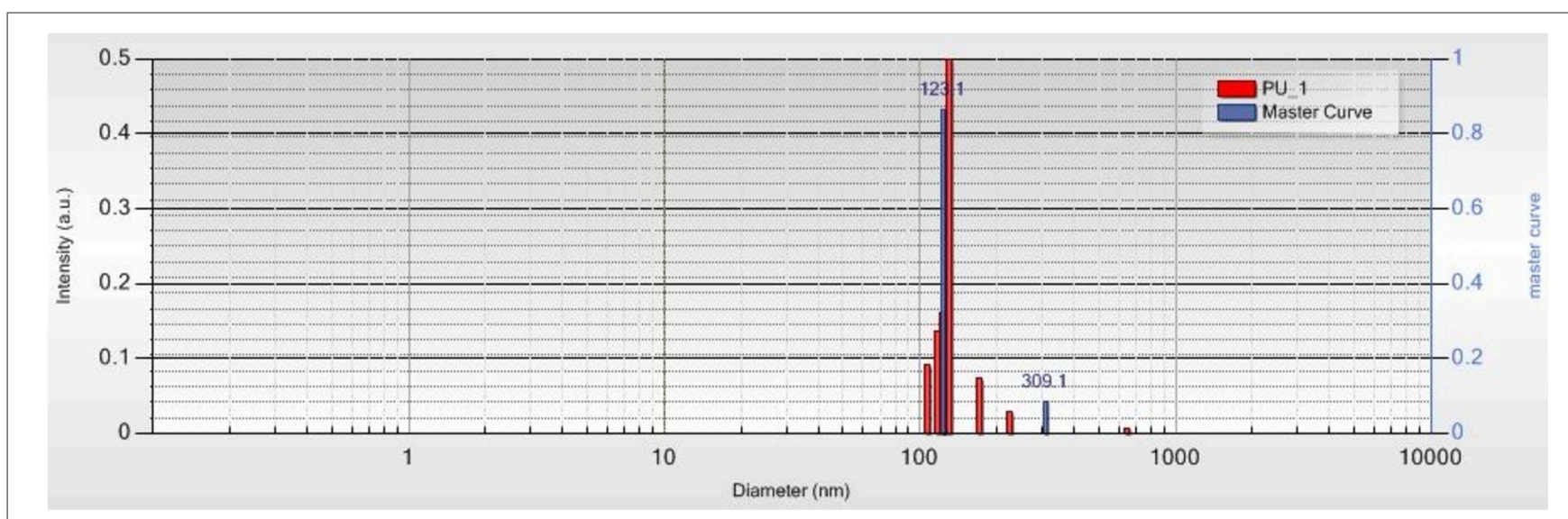

FIGURE 6 | The size distribution of structures from sample PU_1.

to secondary products as allophanate (-NH-CO-NR-CO-O-), biuret (-NH-CO-NR-CO-NH-), and urea (-NH-CO-NH-). Figure 9 presents the overlapped IR spectra obtained for the two samples.

\section{SANS Analysis}

SANS method was used to evaluate the microtextural properties of chitosan-based PU structures. Figure $\mathbf{1 0}$ presents comparative information about the synthesized samples. The calibrated SANS data curves were described with a power-law type scattering, according to the Porod approximation (see Equation 1), used for large scattering objects (where $Q R>>1, R$ being a characteristic, average size of the scattering particles).

$$
I(Q)=A Q^{-p}+B
$$

$A$ is a constant containing instrumental attributes and sample physical characteristics, and $B$ is the incoherent background scattering. In this $Q$ vector range, SANS did not give information about the size of the scattering particles/pores/inclusions; however, it characterized their surface. The value of the $p$ power was characteristic to rough, fractal-like surfaces and interfaces.

\section{In vivo Evaluations}

Animal and human skin models are often used to evaluate the irritation effects of new compounds. Modern and noninvasive techniques were developed to assess the skin parameters such as skin $\mathrm{pH}$, transepidermal water loss (TEWA), melanin and erythema, the level of stratum corneum hydration, sebum, etc. Figures 11, 12 present the changes of transepidermal water loss and erythema levels as main indicators of any irritation effect.

\section{DISCUSSION}

In the present synthesis of the PU structures, HDI was used as a diisocyanate instead of aromatic compounds often used in industrial applications for their better mechanical properties. Studies on PU materials degradation revealed that the main raw materials (polyols and isocyanates) were usually obtained during their decomposition (Bolcu and Borcan, 2005); thus, in 

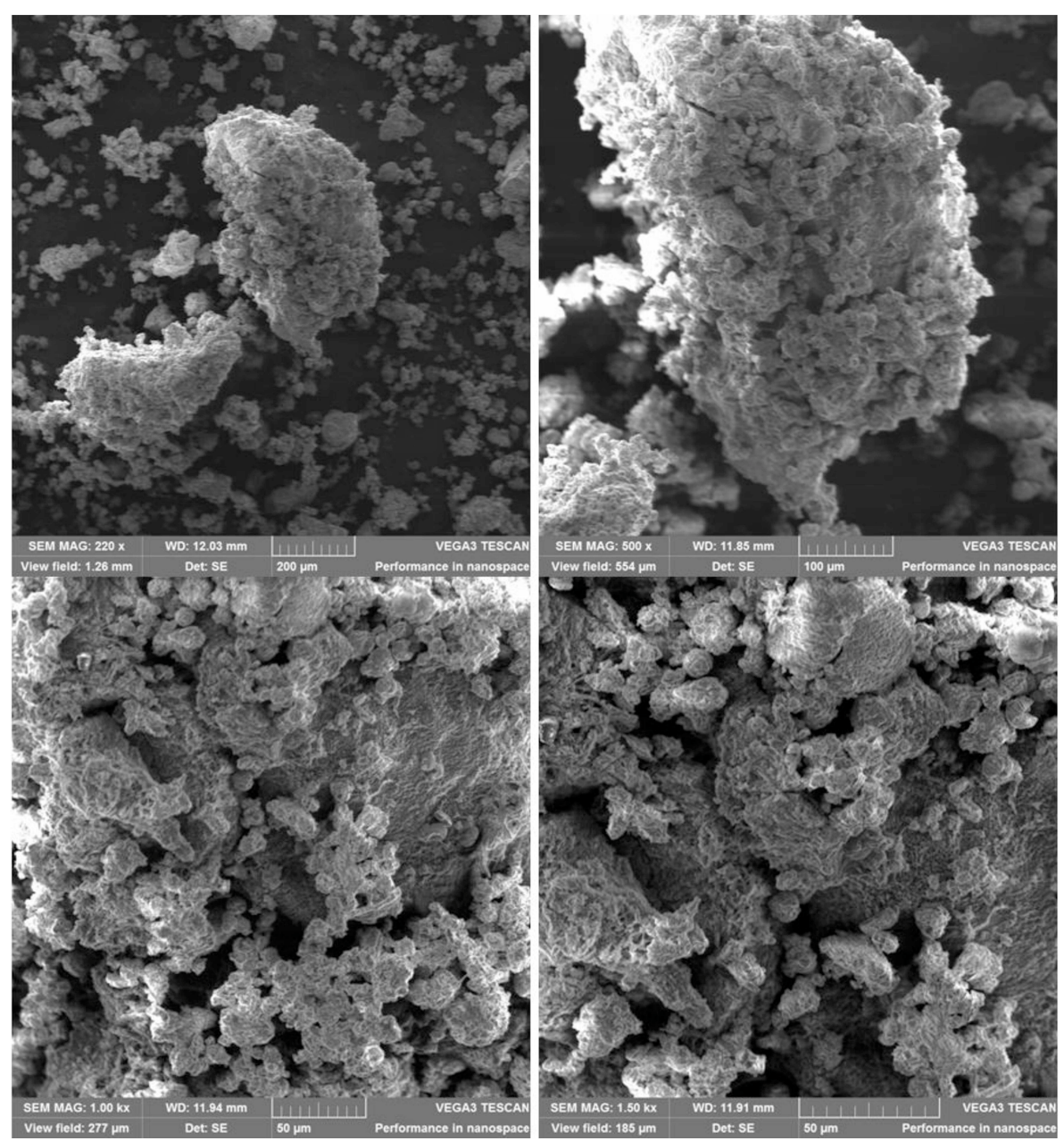

FIGURE 7 | Aspect of structures from sample PU_0 at different magnifications.

the present study, an aliphatic diisocyanate has been chosen in order to avoid the introduction of certain aromatic compounds in the human body. Caffeine was used as synthesis catalyst instead of other tertiary amines [1,4-diazabicyclo(2.2.2)octane], tin, or bismuth organic compounds (dibutyl-tin-dilaurate, bismuth neodecanoate; Guhl, 2008); this natural cardiac and central nervous system stimulant was chosen because of its low toxicity. Chitosan has been chosen as a crosslinking agent based on the information about its natural source, ability to swell, capacity to absorb water, and grafting efficiency.

The prolonged release of isosorbide derivatives was obtained by using polyethylene glycol as raw material instead of any other ester polyol that has a faster hydrolysis (Hajnal et al., 2016) and by using a mixture of mono- and di-nitrates (Figure 13): IS-DN does not contain any active hydrogen and it is just physically entrapped inside the polymer matrix, while IS-2-MN and IS-5MN contain a hydroxyl group and an important part of their amount is covalently bound to the PU chains. Literature describes the extended release as a slower delivery of the entrapped drugs at therapeutic level for 8-12 $\mathrm{h}$ while a prolonged release indicates a delivery over a longer and delayed period; Korsmeyer-Peppas model is often used to describe the drug release from polymeric systems (Kakar et al., 2014). Mathematical models have a key role in the interpretation of release profiles; the trend of the present release can be described by the equation $y=2.496 x-3.5833$ $\left(R^{2}=0.9756\right)$, which is specific to a better release than those described in the case of three nano-fibrous scaffolds based on Nylon 6 or polycaprolactam and used as carrier for Cetirizine (Saadatmand et al., 2019).

Bolcu and Borcan (2005) have reported that PU materials are thermally stable up to $300-320^{\circ} \mathrm{C}$ depending on the aliphatic/aromatic character of diisocyanates. The insertion of chitosan in the synthesis and the appearance of allophanates in the reaction between PUs' - NH- and an isocyanate, substitute biuret structures in the reaction between $-\mathrm{NH}_{2}$ and two isocyanate molecules, amides (carboxylic with isocyanate groups), and urea groups in the reaction between primary amines and one isocyanate group, lead to a decreased thermal stability (the degradation begins at $260-280^{\circ} \mathrm{C}$, Figure 4). 

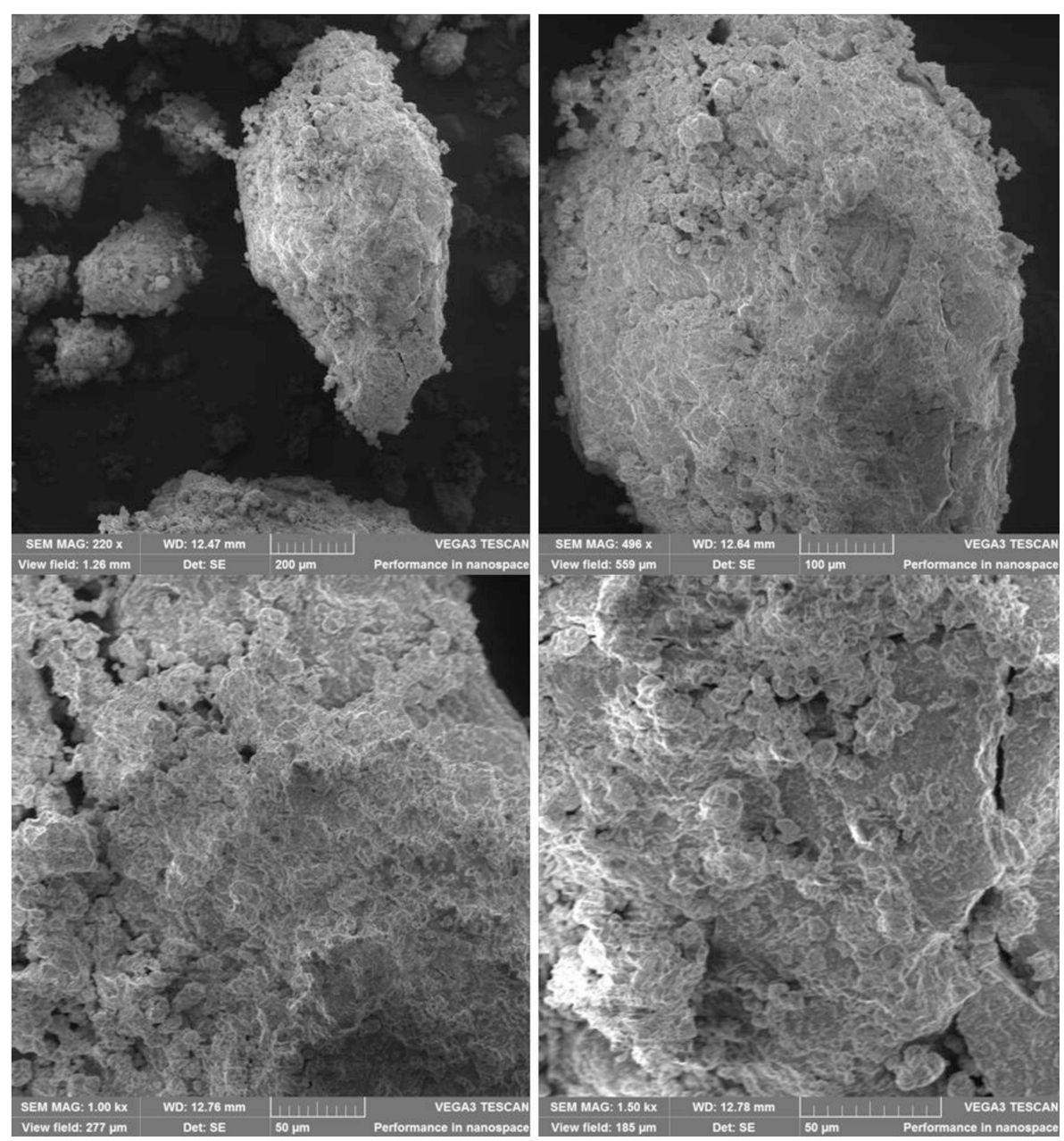

FIGURE 8 | Aspect of structures from sample PU_1 at different magnifications.

The polydispersity, or size heterogeneity of the samples, measured as PDI is a representation of the distribution of different particle populations; PDI is a number between 0.0 for perfectly homogeneous samples and 1.0 for highly heterogeneous samples with multiple particle populations. Carriers with high PDI were extensively employed to enhance the drugs' bioavailability and their release. Danaei et al. (2018) explained a few advantages of drug delivery systems with bigger PDI: the particles of a polydisperse system reach the targeted receptor at different moments and the accumulated effects specific to monodisperse carriers are thus avoided; particles with different sizes have a different capacity to entrap drugs and different degradation and release rates. The Zetasizer measurements confirm the obtaining of multipopulational PU structures that were observed in SEM images (Figures 7, 8), too.

The main functional groups of PU present the following positions of their vibrations in the FTIR spectra: free hydroxyl $\left(3,610-2,870 \mathrm{~cm}^{-1}\right),-\mathrm{NCO}\left(2,280-2,260 \mathrm{~cm}^{-1}\right)$, urethane groups
(1,715-1,650 $\mathrm{cm}^{-1}$ ), and allophanate at $1720 \mathrm{~cm}^{-1}$ (Bolcu and Borcan, 2005). FTIR spectra of our samples PU_0 and PU_1 (Figure 9) are quite similar with a few little differences. This similarity is due to the good isolation of encapsulated isosorbide derivatives on the one hand and to a good wash of free un-encapsulated raw materials during the last step of the synthesis on the other hand. Specific signals of N-H stretching vibrations can be observed at 3,341-3,339 $\mathrm{cm}^{-1}$, stretching vibrations of $-\mathrm{CH}_{2}$ - and $-\mathrm{CH}_{3}$ at $2,932-2,862 \mathrm{~cm}^{-1}$, stretching vibrations of $\mathrm{C}=\mathrm{O}$ from urea and urethane groups at $1,629-1,572 \mathrm{~cm}^{-1},-\mathrm{CH}_{2}$ - deformations at $1,471-1,377 \mathrm{~cm}^{-1}$, stretching vibrations of urethane $\mathrm{C}-\mathrm{O}$ at $1,260-1,256 \mathrm{~cm}^{-1}$ and of ether $\mathrm{C}-\mathrm{O}-\mathrm{C}$ between 1,110 and $1,070 \mathrm{~cm}^{-1}$, while the other signals correspond to deformation vibration of urethane $\mathrm{CO}-$ $\mathrm{O}$ bonds. There were no observed specific signals of free - $\mathrm{NCO}$ (stretching vibrations at $2,260 \mathrm{~cm}^{-1}$ ) and $\mathrm{C}=\mathrm{O}$ of isocyanurate rings $\left(1,690 \mathrm{~cm}^{-1}\right)$.

The significant absorption bands of isosorbide nitrate FTIR spectra were already described in literature (Silvieri 


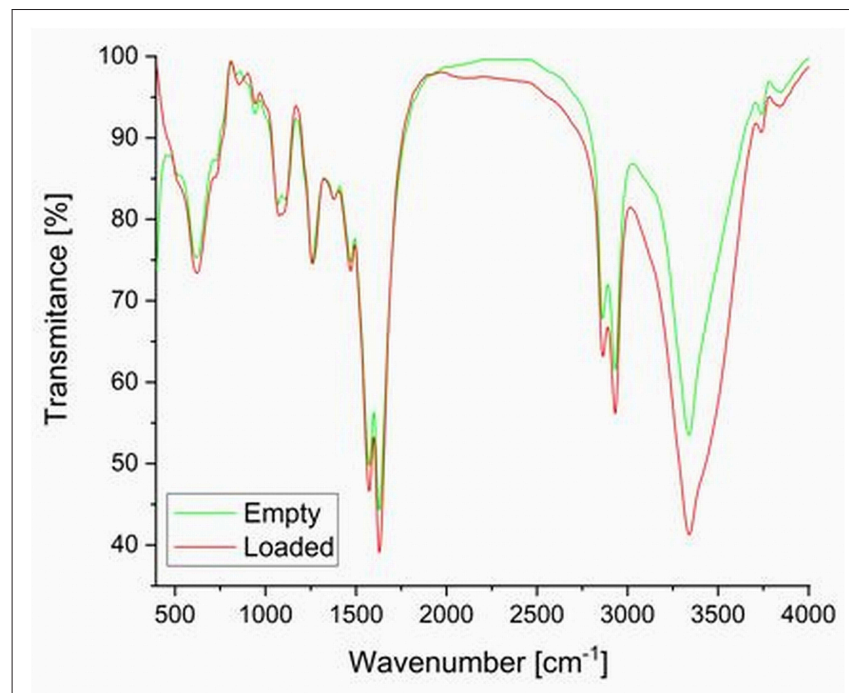

FIGURE 9 | Comparative FT-IR spectra of empty and drug-loaded PU capsules.

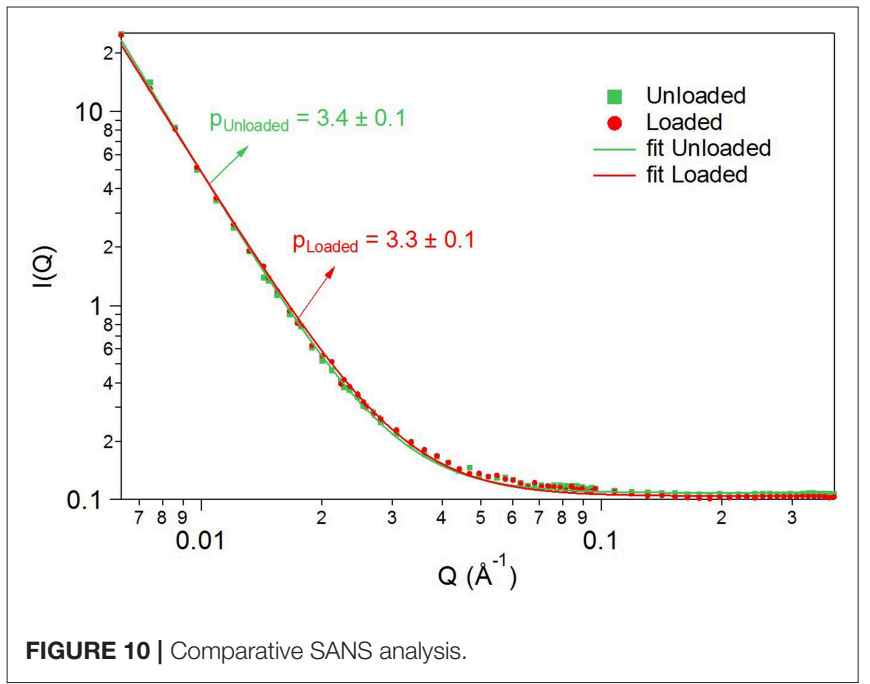

and DeAngelis, 1975): stretching vibrations of aliphatic C-H $\left(2,950-2,850 \mathrm{~cm}^{-1}\right)$, stretching vibrations of asymmetric $\mathrm{NO}_{2}$ $\left(1,665\right.$ and $\left.1,635 \mathrm{~cm}^{-1}\right)$, scissoring vibrations of methylene $\left(1,460 \mathrm{~cm}^{-1}\right)$, stretching vibrations of symmetric $\mathrm{NO}_{2}$ $\left(1,285-1,270 \mathrm{~cm}^{-1}\right)$, stretching vibrations of asymmetric C-O-C $\left(\sim 1,100 \mathrm{~cm}^{-1}\right)$ and stretching vibrations of $\mathrm{O}-\mathrm{NO}_{2}$ $\left(865 \mathrm{~cm}^{-1}\right)$.

The surface fractal-like character of the studied PU samples nanostructure in the available $Q$ scattering vector $[Q=(4 \pi / \lambda)$ $\sin \Theta ; \lambda$, neutron wavelength; $2 \Theta$, scattering angle] range $\left(0.006-0.300 \AA^{-1}\right)$ has been shown by SANS. The smallangle scattering curves of both (loaded and unloaded) samples showed power exponents: $p_{\text {loaded }}=3.3 \pm 0.1$ and $p_{\text {unloaded }}$ $=3.4 \pm 0.1$ (see raw data and fitted models in Figure 10) corresponding to a network-like three-dimensional porous
PU skeleton constructed of units with sizes larger than the nanometric scale range, having a rough surface and thus a large surface area. Complementary to the results obtained by SEM, where the texture of the material has been studied on a micrometric level, SANS evidenced surface fractal-like character for both samples at a smaller size scale (size range approximately $20-1,000 \AA$ ) in the whole studied volume. This proves that the PU nanostructure was not affected by the drug encapsulation.

The evaluation of skin irritation potential represents a new alternative method to assess the hazard of a new synthesized compound. The skin sensitivity is a very good and fair parameter used in many toxicity assays on new cosmetics, but it can be generally used in the evaluation of any chemicals. The changes of skin parameters (especially the level of transepidermal water loss and erythema) are fast and directly proportional with the irritation potential of the compounds (Kose et al., 2018). The visual observations were replaced by modern, more accurate, credible and non-invasive techniques. In this 2-week experiment, TEWA differences around $6 \mathrm{~g} / \mathrm{h} / \mathrm{m}^{2}$ were observed after the application of multiple samples, and according to Oestmann et al. (1993), these changes were inside a normal range. Erythema measurements indicated an increase by about 70 units after 15 days; increases of erythema levels were seen in every experiment done in our Phyto-science Research Center either in mice or in human skin experiments in the last 8 years due to the skin sensitivity.

Sodium lauryl sulfate (SLS) is often used as control sample in these irritation potential tests. V.G. Gurita (Ciobotaru) and her team have reported increases of TEWA around $11 \mathrm{~g} / \mathrm{h} / \mathrm{m}^{2}$ and of erythema index approximately 90 units using the same instruments in a 25-h experiment on the skin of healthy human volunteers (Gurita (Ciobotaru) et al., 2019). In another study of our team, SLS solution was used as reference in an assessment of the toxicological profile of betulin entrapped in a PU carrier (Borcan et al., 2018c); they presented comparative values of TEWL and erythema between the PU samples and SLS at 6 days, and important increases were found in the case of the well-known irritative agent (around $4 \mathrm{~g} / \mathrm{h} / \mathrm{m}^{2}$ for the transepidermal water loss and more than 175 units for erythema index).

In conclusion, PU structures were developed by using a polyaddition process between chitosan, an aliphatic isocyanate, and an ether polyol as main raw materials. The obtained polydisperse carrier, consisting of structures between 104 and $310 \mathrm{~nm}$, presents good encapsulation efficiency of isosorbide derivatives (around 70\%), a very slow release, and a good stability against thermal degradation. The carrier structures possess low values of their surface charge, which indicates a high tendency to form clusters, confirmed by SEM images; their maximum absorption was recorded at $345-360 \mathrm{~nm}$. The skin irritation potential of samples, measured on human volunteers as transepidermal water loss and erythema level, did not show important modifications of these parameters in a 15-day experiment. 


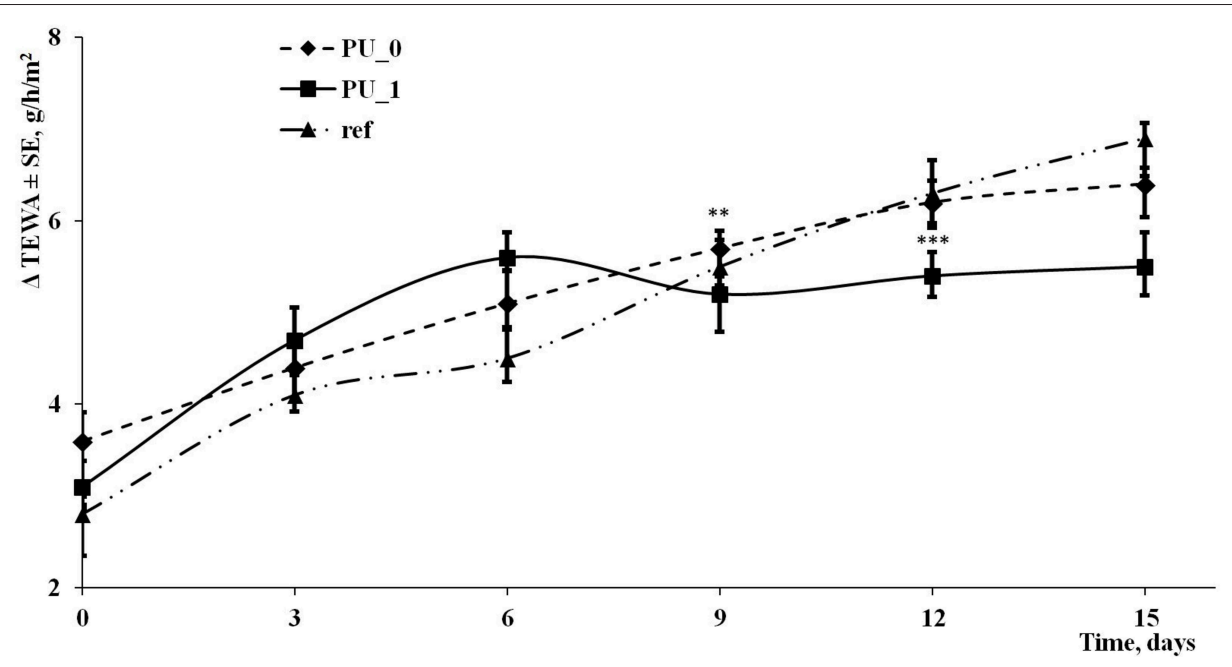

FIGURE 11 | Evolution of TEWA during the experiment.

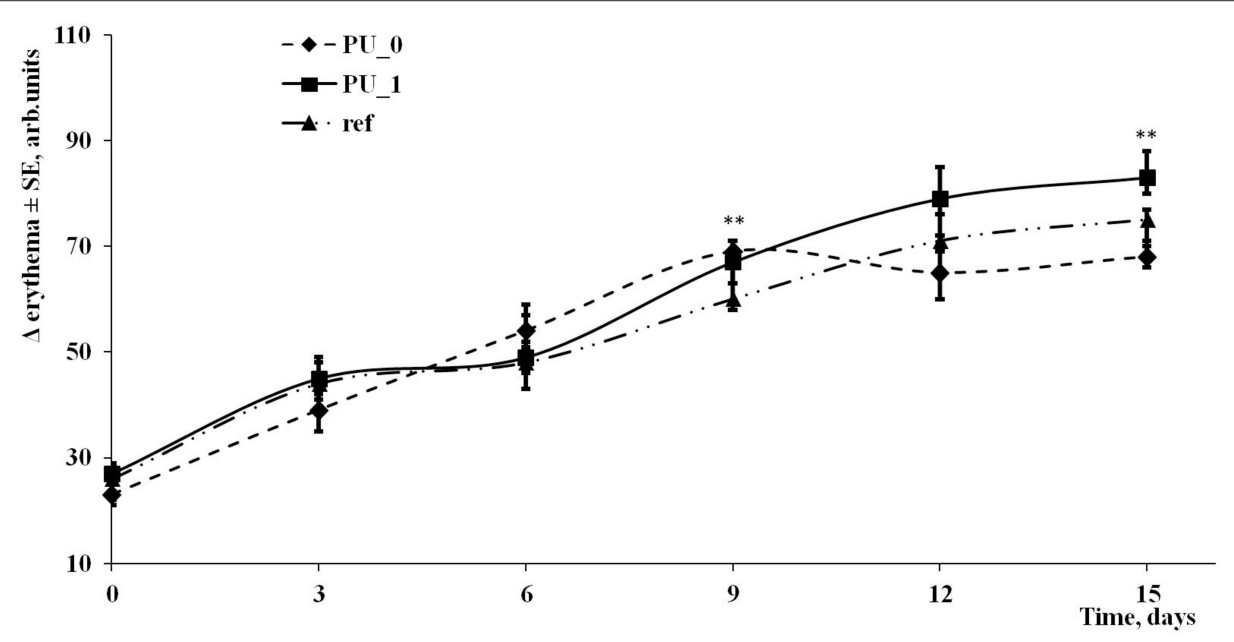

FIGURE 12 | Evolution of erythema during the experiment.

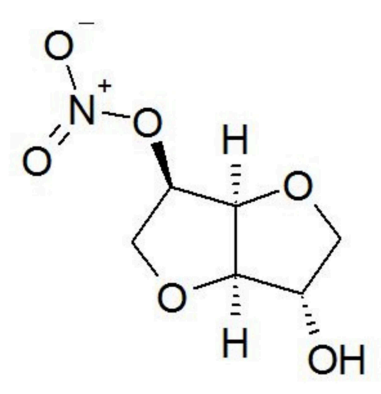

IS-5-MN

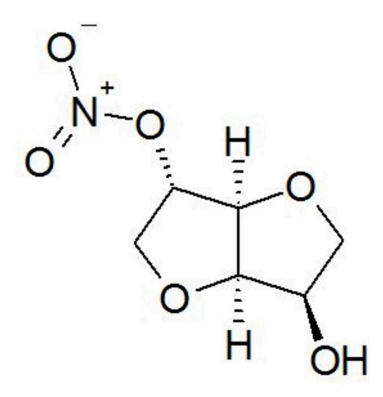

IS-2-MN

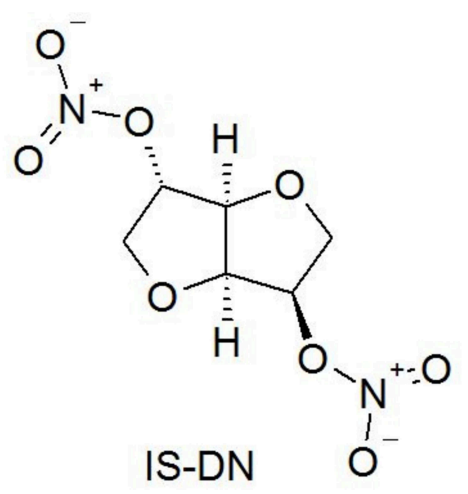

IS-DN

FIGURE 13 | Chemical structures of isosorbide derivatives. 


\section{DATA AVAILABILITY STATEMENT}

All datasets presented in this study are included in the article/supplementary material.

\section{ETHICS STATEMENT}

The studies involving human participants were reviewed and approved by Ethical Committee of Victor Babes University of Medicine and Pharmacy Timisoara, Romania. The patients/participants provided their written informed consent to participate in this study.

\section{AUTHOR CONTRIBUTIONS}

Conceptualization: FB, ZD, and MT. Methodology and investigation: $\mathrm{AL}$ and DB. Software: MT. Resources: FB and

\section{REFERENCES}

Barichello, J. M., Yamakawa, N., Kisyuku, M., Handa, H., Shibata, T., Ishida, T., et al. (2017). Combined effect of liposomalization and addition of glycerol on the transdermal delivery of isosorbide 5-nitrate in rat skin. Int. J. Pharm. 357, 199-205. doi: 10.1016/j.ijpharm.2008.01.052

Basu, A., Farah, S., Kunduru, K. R., Doppalapudi, S., Khan, W., and Domb, A. J. (2016). "Polyurethanes for controlled drug delivery" in Advances in Polyurethane Biomaterials, eds S. L. Cooper and J. Guan (Duxford: Woodhead Publishing), 217-246.

Bolcu, C., and Borcan, F. (2005). The study of the reactions of 2,4-dihydroxybenzophenone with mono- and diisocyanates. Mater. Plast. 42, 35-39.

Bonn, R. (1988). Sustained-release isosorbide mononitrate (50 mg): optimization of a once-daily dosage form for long-term treatment of angina pectoris. Am. J. Cardiol. 61, 12E-14E. doi: 10.1016/0002-9149(88) 90082-3

Borcan, F., Chirita-Emandi, A., Andreescu, N. I., Borcan, L. C., Albulescu, R. C., Puiu, M., et al. (2019). Synthesis and preliminary characterization of polyurethane nanoparticles with ginger extract as a possible cardiovascular protector. Int. J. Nanomed. 14, 3691-3703. doi: 10.2147/IJN.S202049

Borcan, F., Preda, M., Borcan, L. C., Pinzaru, I., Florescu, S., Sisu, E., et al. (2018a). Comparative characterization of birch bark extracts encapsulated inside polyurethane microstructures. Mater Plast. 55, 385-388. doi: 10.37358/MP.18.3.5035

Borcan, F., Soica, C. M., Lazureanu, V., Pinzaru, I. A., Cheveresan, A., and Poenaru, M. (2018b). Toxicological assessment of betulin entrapped in a polyurethane carrier. Mater. Plast. 55, 149-151. doi: 10.37358/MP.18.2.4983

Borcan, L. C., Dudas, Z., Len, A., Fuzi, J., Borcan, F., and Tomescu, M. C. (2018c). Synthesis and characterization of a polyurethane carrier used for a prolonged transmembrane transfer of a chili pepper extract. Int. J. Nanomed. 13, 7155-7166. doi: 10.2147/IJN.S181667

Bouchemal, K., Briançon, S., Perrier, E., Fessi, H., Bonnet, I., and Zydowicz, N. (2004). Synthesis and characterization of polyurethane and poly(ether urethane) nanocapsules using a new technique of interfacial polycondensation combined to spontaneous emulsification. Int. J. Pharm. 269, 89-100. doi: 10.1016/j.ijpharm.2003.09.025

Danaei, M., Dehghankhold, M., Ataei, S., Hasanzadeh Davarani, F., Javanmard, R., Dokhani, A., et al. (2018). Impact of particle size and polydispersity index on the clinical applications of lipidic nanocarrier systems. Pharmaceutics 10:E57. doi: 10.3390/pharmaceutics10020057

Gama, N. V., Ferreira, A., and Barros-Timmons, A. (2018). Polyurethane foams: past, present, and future. Materials 11, 1-35. doi: 10.3390/ma11101841

Guhl, D. (2008). Alternatives to DBTL Catalysts in Polyurethanes - A Comparative Study. (Berlin: European Coatings Conference).
AV. Writing-original draft preparation: FB and ZD. Writingreview and editing: FB, AL, and MT. Project administration: FB. All authors contributed to the article and approved the submitted version.

\section{FUNDING}

This article was supported by the grant 5EXP/1244/30.01.2020 from Victor Babes University of Medicine and Pharmacy, Timisoara, Romania.

\section{ACKNOWLEDGMENTS}

FB would like to express his special appreciation and thanks to his advisors for the great support and kind advice throughout his $\mathrm{PhD}$ research studies (Prof. R. Nutiu and Assoc. Prof. Ctin. Bolcu from West University Timisoara, Romania).
Gunasekara, N. S., and Noble, S. (1999). Isosorbide 5-mononitrate: a review of a sustained-release formulation (Imdur) in stable angina pectoris. Drugs 57, 261-277. doi: 10.2165/00003495-199957020-00016

Gurita (Ciobotaru), V.G., Pavel, I.Z., Borcan, F., Moaca, A., Danciu, C., Diaconeasa, Z., et al. (2019). Toxicological evaluation of some essential oils obtained from selected Romania Lamiaceae Species in complex with hydroxypropyl - gamma-cyclodextrin. Rev. Chim. Bucharest 70, 3703-3707.

Hajnal, K., Gabriel, H., Aura, R., Erzsébet, V., and Blanka, S. S. (2016). Prodrug strategy in drug development. Acta Med. Maris. 62, 356-362. doi: 10.1515/amma-2016-0032

Hasirci, N., and Aksoy, E. A. (2007). Synthesis and modifications of polyurethanes for biomedical purposes. High Perform. Polym. 19, 621-637. doi: $10.1177 / 0954008307081203$

Hirayama, F., Hirashima, N., Abe, K., Uekama, K., Ijitsu, T., and Ueno, M. (1988). Utilization of diethyl-beta-cyclodextrin as a sustained-release carrier for isosorbide dinitrate. J. Pharm. Sci. 77, 233-236. doi: 10.1002/jps.2600770310

Kakar, S., Singh, R., and Semwal, A. (2014). Drug release characteristics of dosage forms: a review. J. Coastal Life Med. 2, 332-336.

Kikuchi, I. S., Cardoso Galante, R. S., Dua, K., Malipeddi, V. R., Awasthi, R., Ghisleni, D. D. M., et al. (2017). Hydrogel based drug delivery systems: a review with special emphasis on challenges associated with decontamination of hydrogels and biomaterials. Curr. Drug Deliv. 14, 917-925. doi: 10.2174/1567201813666161205130825

Kim, H. J., Kang, M. S., Knowles, J. C., and Gong, M. S. (2014). Synthesis of highly elastic biocompatible polyurethanes based on bio-based isosorbide and poly(tetramethylene glycol) and their properties. J. Biomater. Appl. 29, 454-464. doi: $10.1177 / 0885328214533737$

Kim, H. N., Lee, D. W., Ryu, H., Song, G. S., and Lee, D. S. (2019). Preparation and characterization of isosorbide-based self-healable polyurethane elastomers with thermally reversible bonds. Molecules 24:1061. doi: 10.3390/molecules24061061

Kocyigit, D., Gurses, K. M., Yalcin, M. U., and Tokgozoglu, L. (2017). Traditional and alternative therapies for refractory angina. Curr. Pharm. Design 23, 1098-1111. doi: 10.2174/1381612823666161123145148

Kose, O., Erkekoglu, P., Sabuncuoglu, S., and Kocer-Gumusel, B. (2018) Evaluation of skin irritation potentials of different cosmetic products in Turkish market by reconstructed human epidermis model. Regul. Toxicol. Pharmacol. 98, 268-273. doi: 10.1016/j.yrtph.2018.08.010

Munteanu, M. F., Ardelean, A., Borcan, F., Trifunschi, S. I., Gligor, R., Ardelean, S. A., et al. (2017). Mistletoe and garlic extracts as polyurethane carriers-a possible remedy for Choroidal Melanoma. Curr. Drug Deliv. 14, 1178-1188. doi: $10.2174 / 1567201814666170126113231$

Oestmann, E., Lavrijsen, A. P., Hermans, J., and Ponec, M. (1993). Skin barrier function in healthy volunteers as assessed by transepidermal water loss and 
vascular response to hexyl nicotinate: intra- and inter-individual variability. $B r$. J. Dermatol. 128, 130-136. doi: 10.1111/j.1365-2133.1993.tb15141.x

Polakowska, M., Orzelska-Gorka, J., and Talarek, S. (2016). Drugs modulating the L-arginine: NO: cGMP pathway-current use in therapy. Curr. Issues Pharm. Med. Sci. 29, 14-20. doi: 10.1515/cipms-2016-0004

Prakash, A., and Markham, A. (1999). Long-acting isosorbide mononitrate. Drugs 57, 93-100. doi: 10.2165/00003495-199957010-00008

Quan, H., Park, Y. K., Kim, S. K., Heo, S. J., Koak, J. Y., Han, J. S., et al. (2016). Surface characterization and human stem cell behaviors of zirconia implant disks biomimetic-treated in simulated body fluid. Int. J. Oral Maxillofac. Implants 31, 928-938. doi: 10.11607/jomi.4376

Raddino, R., Caretta, G., Bonadei, I., Teli, M., Vizzardi, E., and Cas, L. D. (2010). Differences between nitrates: role of isosorbide 2-mononitrate. J. Cardiovasc. Med. (Hagerstown) 11, 486-492. doi: 10.2459/JCM.0b013e328335fb8c

Saadatmand, M. M., Yazdanshenas, M. E., Khajavi, R., Mighani, F., and Toliyat, T. (2019). Patterning the surface roughness of a nano fibrous scaffold for transdermal drug release. Int. J. Nano Dimens 10, 78-88.

Silvieri, L. A., and DeAngelis, N. J. (1975). Isosorbide dinitrate. Anal. Profiles Drug Subst. 4, 225-244. doi: 10.1016/S0099-5428(08)60015-5

Solano-Umana, V., Vega-Baudrit, J. R., and González-Paz, R. (2015). The new field of the nanomedicine. Int. J. Appl. Sci. Technol. 5, 79-88.

Steinbach, S. C., Triani, R., Bennedsen, L., Gabel, A., Haeusler, O., Wohlrab, J., et al. (2017). Retarder action of isosorbide in a microemulsion for a targeted delivery of ceramide NP into the Stratum corneum. Pharmazie 72, 440-446. doi: 10.1691/ph.2017/7004

Thadani, U., and Rodgers, T. (2006). Side effects of using nitrates to treat angina. Expert Opin. Drug Saf. 5, 667-674. doi: 10.1517/14740338.5.5.667
Tsai, F.-Y., Chen, C.-J., and Chien, C.-S. (1994). Determination of isosorbide nitrate and its analogues in pharmaceuticals by high-performance liquid chromatography. J. Food Drug Anal. 2, 271-280.

Turner, P. V., Brabb, T., Pekow, C., and Vasbinder, M. A. (2011). Administration of substances to laboratory animals: routes of administration and factors to consider. J. Am. Assoc. Lab. Anim. Sci. 50, 600-613.

Vermette, P., and Griesser, H. J. (2001). Biomedical Applications of Polyurethanes. Georgetown, DC: Eurekah.com.

Yang, G. M., Kuo, J. F., and Woo, E. M. (2006). Preparation and control-release kinetics of isosorbide dinitrate microspheres. J. Microencapsul. 23, 622-631. doi: 10.1080/02652040600776465

Yao, Y., Feng, Y., and Lin, W. (2015). Systematic review and meta-analysis of randomized controlled trials comparing compound danshen dripping pills and isosorbide dinitrate in treating angina pectoris. Int. J. Cardiol. 182, 46-47. doi: 10.1016/j.ijcard.2014.12.112

Conflict of Interest: The authors declare that the research was conducted in the absence of any commercial or financial relationships that could be construed as a potential conflict of interest.

Copyright (๑) 2020 Borcan, Len, Bordejevic, Dudás, Tomescu and Valeanu. This is an open-access article distributed under the terms of the Creative Commons Attribution License (CC BY). The use, distribution or reproduction in other forums is permitted, provided the original author(s) and the copyright owner(s) are credited and that the original publication in this journal is cited, in accordance with accepted academic practice. No use, distribution or reproduction is permitted which does not comply with these terms. 